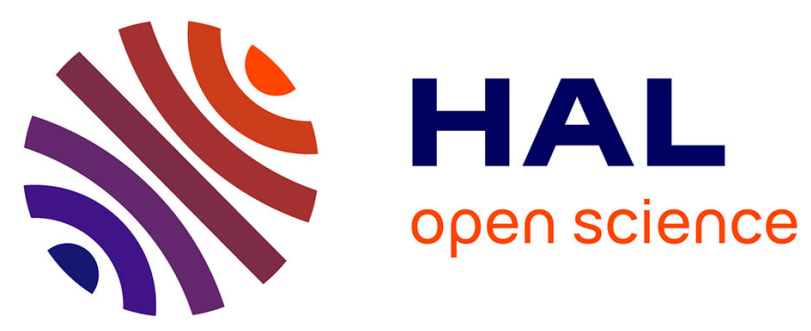

\title{
MINIEMULSIONS USING STATIC MIXERS: PART 2. CO-EMULSIFICATION AND COMPOSITE MATERIALS USING SMX STATIC MIXERS
}

\author{
Gholamali Farzi, Elodie Bourgeat-Lami, Timothy Mckenna
}

\section{- To cite this version:}

Gholamali Farzi, Elodie Bourgeat-Lami, Timothy Mckenna. MINIEMULSIONS USING STATIC MIXERS: PART 2. CO-EMULSIFICATION AND COMPOSITE MATERIALS USING SMX STATIC MIXERS. Canadian Journal of Chemical Engineering, 2011, 89 (6), pp.1434-1440. 10.1002/cjce.20514 . hal-00723726

\section{HAL Id: hal-00723726 \\ https://hal.science/hal-00723726}

Submitted on 8 Oct 2021

HAL is a multi-disciplinary open access archive for the deposit and dissemination of scientific research documents, whether they are published or not. The documents may come from teaching and research institutions in France or abroad, or from public or private research centers.
L'archive ouverte pluridisciplinaire HAL, est destinée au dépôt et à la diffusion de documents scientifiques de niveau recherche, publiés ou non, émanant des établissements d'enseignement et de recherche français ou étrangers, des laboratoires publics ou privés. 


\title{
Miniemulsions Using Static Mixers:
}

Part 2. Co-emulsification and composite materials using SMX static mixers.

\author{
G.A.Farzi ${ }^{1}$, E. Bourgeat-Lami ${ }^{1}$, T.F.L. McKenna ${ }^{1, *}$ \\ ${ }^{1}$ CNRS-LCPP/CPE, Bât.F308, 43 Bd. du 11 Novembre 1918, B.P.2077, 69616, Villeurbanne, \\ Cedex, France. \\ *tim.mckenna@chee.queensu.ca
}

\begin{abstract}
:
A 50:50 mixture of methylmethacrylate (MMA) and butyl acrylate (BA) was emulsified, then polymerised using different static mixers. It was shown that the emulsification behaviour was very different from that observed for MMA alone under similar conditions. It was shown that the hydrophobicity of the monomers had a strong influence on the droplet size and stability. It was also shown that the amount of work done on the emulsion is important for obtaining polymerisable droplets, and that monomer systems that are difficult to miniemulsify with a low energy system can in fact be made to form stable emulsions simply by changing the emulsification conditions. Finally it was shown that when the miniemulsification conditions are correctly chosen, it is possible to generate miniemulsion dispersions containing silica that can be successfully polymerised to produce silica/polyacrylic nanocomposites.
\end{abstract}

Key Words: Emulsification, Static mixer, Droplet size, Miniemulsion polymerisation, Hydrophobicity, Silica Particles, Nanocomposite,

\section{Introduction}

A polymerisation system for the production of polymeric latex generally consists of five principle components including, continuous phase (generally water), surfactant(s), monomer(s), a hydrophobic agent and initiator. ${ }^{1}$ In this paper we will focus on miniemulsion systems rather than macroemulsions (conventional emulsion polymerisation). Miniemulsion polymerisation preserves certain advantages of conventional emulsion polymerisation in that it allows us to use the same (or similar) monomer and reactor systems, while overcoming some of its limitations and opening the door to novel applications. ${ }^{1-3}$ The main difference 
between conventional and miniemulsion polymerisation lies in the mechanism of particle creation. $^{1-3}$ In conventional emulsion polymerisation micellar nucleation is typically the principle means of particle formation. In miniemulsions, the droplets are formed by imposing shear stress on a mixture of all of the reactants before the reaction begins. If this is done correctly, the droplets will be small enough to successfully capture free radicals generated in the aqueous phase (using the same type of initiator system as in macroemulsions), and will behave as small individual reactors; ideally becoming particles in a 1 to 1 copy. This means that oil soluble compounds or hydrophobised inorganic materials can be directly integrated into the polymer particle ab initio to make hybrid or composite materials, respectively. Of course, this can be done in conventional macroemulsion systems, but it is significantly more difficult. In addition, the creation of particles prior to the reaction can be of benefit as this allows one to control the initial state of the polymerisation in a manner that cannot be done in emulsion systems.

The first essential step in miniemulsion polymerisation is therefore the emulsification of the oil and water phases using some type of high shear mixer in order to break up the monomer phase in to nanodroplets, and reach average droplet diameters on the order of 50$300 \mathrm{~nm}$. A variety of devices including ultrasonic dismembrators (US), high-pressure homogenisers, ${ }^{4,5}$ rotor stator mixers (RS), ${ }^{6,7}$ ultra-turrax homogenisers and stirring have been used for the formation of droplets in miniemulsion range; i.e. with diameters on the order of $100-500 \mathrm{~nm} .{ }^{8,9}$ US is convenient for laboratory investigation because it is rapid, can be used for viscous fluids and can make very small droplets. On the other hand, it is not particularly well-adapted for industrial production, whereas devices like rotor stator and high pressure homogenisers can be used to create a homogenous miniemulsion with small particles on a commercial scale. ${ }^{9}$ Homogenisation devices for miniemulsification have been discussed in a number of recent papers, and reader is referred to them for more information. ${ }^{2,3,10,11}$ In this paper, we will focus on the use of static mixers, for the reasons discussed in Part 1 of this work. ${ }^{12}$ Very briefly, static mixers (SM) are very commonly used in industrial situations, are commercially available, and can be used in continuous processes. We have shown that they are viable emulsification devices; however it is necessary to further our understanding of the miniemulsification process with this type of device.

Static mixers (also referred to as motionless mixers) are solid elements of appropriate shape with no moving parts that are placed in a tube, and liquid (or mixture of phases) is circulated over them using a pump. They work by successively dividing, rotating and 
recombining the flow, and provide very uniform mixing with lower shear rates than one finds in US or RS type mixers and relatively low energy requirements. ${ }^{6,12,13,14}$

Very few reports can be found in the literature related to the use of static mixers as devices for miniemulsification. To the best of our knowledge, Ouzineb et al. ${ }^{6}$ were the first to propose SM as a means of generating miniemulsions, and compared them to RS and US as means of generating miniemulsions of styrene or butyl methacrylate. They showed that SM used significantly less energy per kilo of latex than the other devices.

In Part 1, we have shown that it is possible to control the average droplet size of MMA miniemulsions by varying the flow rates through the mixing elements, the number of elements in series, and the surfactant concentration. ${ }^{12}$ However it turns out that while a given set of emulsification conditions (device, flow rates, emulsification times) works for one formulation, small changes in composition might make it difficult or impossible to generate a polymerisable dispersion of droplets using the same conditions. In the current paper, we present an investigation of the differences between emulsifying a single monomer and emulsifying mixtures of monomers of different water solubilities. In addition, the role of the configuration of the static mixers that make up the emulsification system on droplet size, stability and ease of polymerisation (in the sense that we obtain a 1:1 mapping of droplets into particles) were examined. Once appropriate conditions were identified, they were used to investigate the possibility of producing silica-polyacrylic composite materials.

\section{Experimental}

\section{Materials}

The monomers used in this study were methylmethacrylate (MMA), butyl acrylate (BuA), and styrene (STY) all obtained from ACROS. The hydrophobic agents, n-hexadecane (HD, 99\%) and octadecyl acrylate (ODA, 97\%) were obtained from ACROS and ALDRICH, respectively. All compounds were used as received. Disponil A3065 and Disponil FES 32S are non-ionic and anionic surfactants, respectively. They were graciously supplied by COGNIS France as a solution of 65 and 32 percent active matter in water, respectively. Sodium dodecyl sulphate (SDS) was obtained from ACROS and used as received. Deionised water was used as the continuous phase.

The aqueous silica suspension used in this study was graciously supplied by Clariant (France). The main characteristics of this suspension, referred to as GEN33 are the following: the specific surface area was determined from nitrogen adsorption isotherms to be $50.5 \mathrm{~m}^{2} / \mathrm{g}$, 
the diameter of the silica particles and polydispersity index (PI) were determined by DLS using a Malvern Autosizer and were $78 \mathrm{~nm}$ and 0.02, respectively. The solid content and the suspension $\mathrm{pH}$ were respectively $27 \%$ and 9.57. $\gamma$-methacryloxy propyl trimethoxysilane (MPTMS, Acros organics) was used as coupling agent through this work. ${ }^{15}$ Absolute ethyl alcohol (99.8\%) and methyl alcohol (99.9\%) were obtained from Carlo Erba, and used as received.

\section{Miniemulsification procedure}

Miniemulsions were prepared using 2 formulations. When SDS was used as the surfactant, $0.14 \mathrm{~g}$ SDS was dissolved in $70 \mathrm{~g}$ water in one beaker that was mixed for 30 minutes using a magnetic stirrer bar at room temperature. The hydrophobic agent (1.4 grams of HD) and 28 grams of monomer (MMA or a 50:50 w/w mixture of MMA and BA) were mixed in another beaker. In the case where the mixed surfactant system was used, the aqueous phase was prepared by dissolving $0.17 \mathrm{~g}$ of the anionic surfactant and $0.26 \mathrm{~g}$ of the non-ionic surfactant (these amounts refer to the active fraction of the surfactants) in $70 \mathrm{~g}$ of deionised water. The oil phase was prepared by mixing an appropriate amount of hydrophobic agent (ODA or HD, amounts specified below) in the monomer(s). Each of the oil and aqueous phase mixtures for a given formulation were stirred separately using a magnetic stirrer for approximately half an hour. The organic phase was then added to the aqueous phase under gentle agitation with a magnetic stirrer and then emulsified.

Figure 1 shows a general configuration of SM assembly in which the mixture of the two phases is placed in a reservoir with a magnetic stirrer, and then circulated through a tube (or tubes) containing the SM elements. The two types of SM investigated here are shown in Figure 2. In the initial part of this study, polyacetal mixers (PAC) were used for emulsification (see Part 1 for more details). ${ }^{12}$ In this case, the SMs were housed in a tube with an interior diameter (ID) of $1 \mathrm{~cm}$ and a length of $100 \mathrm{~cm}$, each containing bundles of 4 mixing elements $5 \mathrm{~cm}$ in length and $6.4 \mathrm{~mm}$ in diameter. When SMX elements were used, they were housed in a polytetrafluoroethylene (PTFE) tube with an interior diameter of $8 \mathrm{~mm}$. The elements themselves were $8 \mathrm{~mm}$ in length and $8 \mathrm{~mm}$ in diameter, and 7 of them were housed in the PTFE tube. Ultrasonication (US) was used as reference homogenisation device. Sonication was performed using a Branson Ultrasonic dismembrator (model CV26) set at 480W. 


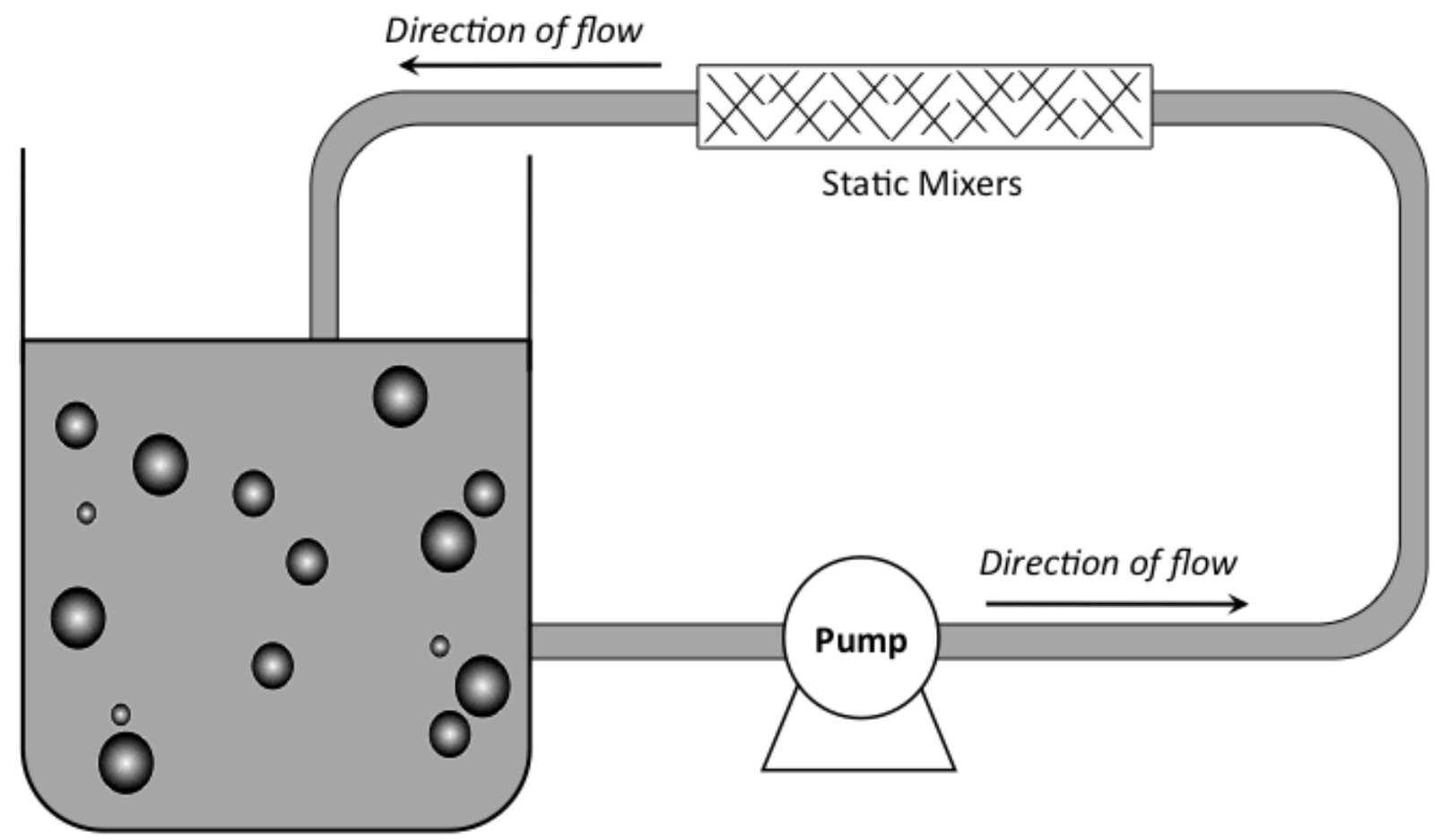

Figure 1. Schematic diagram of the emulsification set-up for the static mixer.


Figure 2. Static mixers used in this study. Top: PAC mixers and bottom: SMX mixers by Sulzer (courtesy of Sulzer Chemtech). 


\section{Miniemulsion polymerisations}

The miniemulsion polymerisations were carried out in a cylindrical glass batch reactor (150 $\mathrm{mL}$ ) with a nitrogen inlet for all the samples. After introduction of the miniemulsion into the reactor, nitrogen was bubbled through the solution for 30 minutes in order to eliminate the oxygen before beginning the polymerisation process. Once this step was completed, the mixture was brought to the desired reaction temperature and the initiator, APS, was added to the batch reactor.

The reactor contents were mixed during polymerisation with a glass anchor stirrer at a constant speed of $250 \mathrm{rpm}$ and the temperature was kept constant at $70^{\circ} \mathrm{C}$, using water circulation from a thermostatic bath. Samples were periodically withdrawn to follow the particle size and size distribution, as well as conversion which were measured by gravimetry.

\section{Characterization}

The intensity average droplet and polymer particle size and polydispersity of miniemulsions or latexes were measured with a Malvern Autosizer. The miniemulsions were considered stable if there was no change (within estimated experimental error of $10 \mathrm{~nm}$ ) in the average droplet size after approximately 4 hours. Complete droplet size distributions reported for the miniemulsions were measured using the Beckman-Coulter LS-230 (Static Light scattering). The ratio of the number of particles to the number of droplets $\left(\mathrm{N}_{\mathrm{p}} / \mathrm{N}_{\mathrm{d}}\right)$ was monitored during the reaction and plotted against conversion.

\section{Results and Discussion}

\section{Miniemulsion of MMA/BuA mixtures}

The main objective of this work is to study the effect of a mixed monomer system (MMA/BuA 50/50 wt\%) and to find the acceptable conditions for miniemulsification of this mixture and its subsequent polymerisation. An example of the challenge posed by this problem is illustrated in Figure 3. It was shown in Part 1 that it was possible to create a MMA miniemulsion with a volume average diameter of $212 \mathrm{~nm}$ after 30 minutes of homogenisation over the PAC mixers at a flow rate of $61 \mathrm{~mL} \cdot \mathrm{s}^{-1}$ using the SDS formulation described above. However, when the same formulation and homogenisation conditions were applied to a 50:50 (w/w) mixture of MMA and BA, a bimodal droplet size distribution is obtained. The smaller, well-defined mode had a much larger volume average droplet size of $320 \mathrm{~nm}$. Polymerisation of these samples resulted in a latex with particles considerably smaller than the miniemulsion droplets leading to a $\mathrm{N}_{\mathrm{p}} / \mathrm{N}_{\mathrm{d}}$ ratio of 5.2 (using the $320 \mathrm{~nm}$ diameter mode for the calculation). 
This means that significant particle renucleation occurred in this system. On the other hand, emulsification of the MMA+BA samples using US for 120 seconds led to a stable miniemulsion with a volume average droplet size of $155 \mathrm{~nm}$ (vs. 130 for MMA alone in Part 1 under the same conditions), and a relatively narrow droplet size distribution. Polymerisation of this sample showed that $\mathrm{N}_{\mathrm{p}} / \mathrm{N}_{\mathrm{d}}=0.95$ throughout the reaction, suggesting that droplet nucleation was predominant. Clearly even moderate changes in formulation can have a large impact on our ability to create a stable dispersion. The PAC set-up cannot be used to make a stable miniemulsion of MMA+BA, and while US is a feasible alternative in this case, the average droplet diameter is almost 20 percent larger for the mixture than for MMA alone (a $72 \%$ increase in the average volume). However it remains to be explained why one can make a dispersion of MMA+BA with the US set-up, but not with the PAC static mixers.

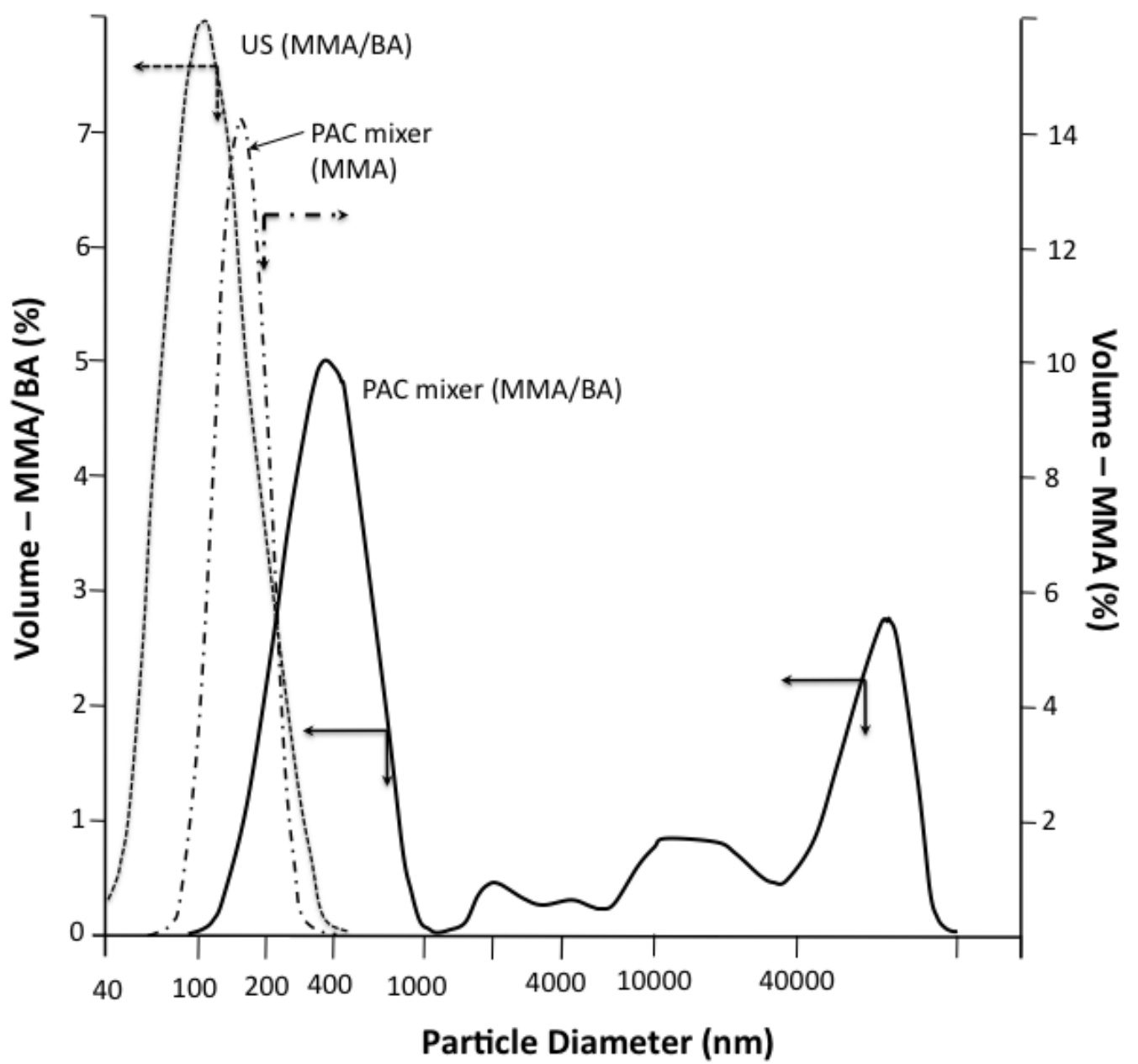

Figure 3. Droplet size distributions in miniemulsions of MMA/BuA (50/50) and of MMA alone created by PAC static mixers and by US. The volume average droplet size is $320 \mathrm{~nm}$ for PAC and 155 for US. The formulations were similar: $1.4 \mathrm{~g} / 1 \mathrm{SDS}, 14 \mathrm{~g} \mathrm{HD}, 280 \mathrm{~g}$ monomer, $700 \mathrm{~g}$ deionised water. The monomer was either 100\% MMA or a 50:50 (w/w) mixture of MMA and BA. 
In order to better understand the relationship between the formulation and the emulsification step, additional homogenisations were performed using single monomer systems with the formulations shown in Table 1. This mixed surfactant system was chosen in an attempt to improve upon the results in Figure 3. The droplet size distribution of three different monomers of different water solubilities are shown in Figure 4, the evolution of the volume average droplet size of these miniemulsions as a function of homogenisation time is shown in Figure 5, and the droplet size distributions of MMA+BA emulsions made using the mixed surfactant formulation and the two different homogenisation systems discussed until now are shown in Figure 6.

First of all, it can be seen that once again, the PAC set-up can be used to generate a stable MMA miniemulsion with an average particle size of $200 \mathrm{~nm}$. While this is slightly smaller than those obtained with the SDS-based formulation (212 $\mathrm{nm}$ in Part 1), the difference between the two is within the limit of sensitivity of the apparatus used for this measurement so it is fair to say that the mixed surfactant system gives essentially the same results as the SDS system, leading us to believe that the results of the two formulations are comparable.

Interestingly enough, the results in Figure 4 shows that it is possible to use the SM setup with the PAC mixers to emulsify BA alone. Thus this set-up can be used to make MMA miniemulsions, BA miniemulsions, but, as shown in Figure 6, not for the mixture of MMA+BA even with this new formulation. In addition, it appears that it is not possible to obtain a monomodal miniemulsion of styrene. Once again, using the same formulation, one can make a stable, monomodal miniemulsion of the MMA+BA mixture using the US as the homogeniser.

Table 1. Miniemulsion recipe

\begin{tabular}{ccccc}
\hline Water & Monomer & Hydrophobic agent & Surfactant & Initiator \\
\hline $69.35 \mathrm{~g}$ & $28.1 \mathrm{~g}$ & $2 \mathrm{~g}(\mathrm{ODA})$ & $0.17 \mathrm{~g}$ TA, 0.26g TN & $0.12 \mathrm{~g}$ APS \\
\hline
\end{tabular}

$\mathrm{TN}=$ Disponil A3065 and TA = Disponil FES 32S 


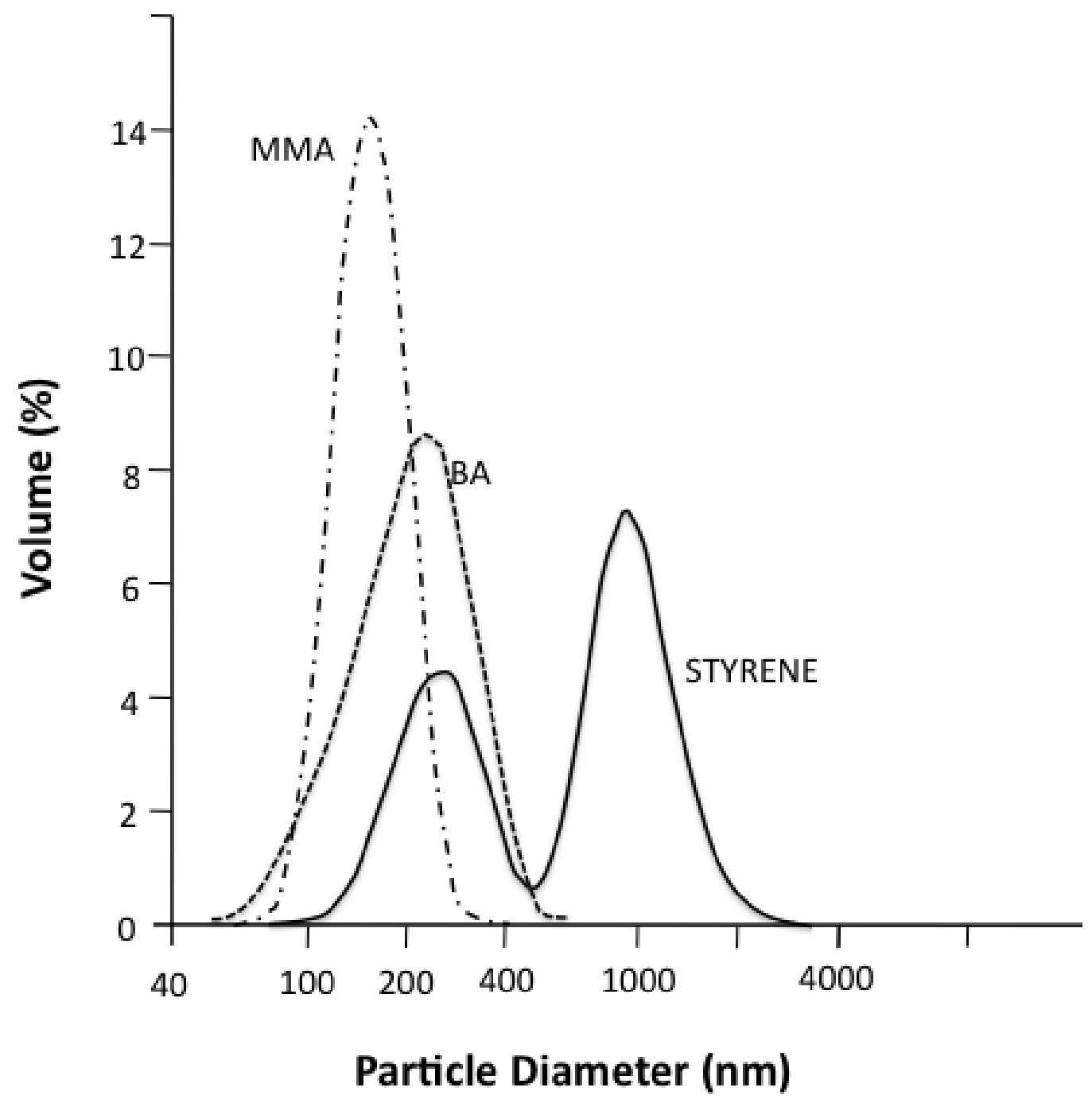

Figure 4. Droplet size distribution in miniemulsions of MMA, of BA, and of Styrene created by PAC static mixers. The water solubilities of STY, BA and MMA are 3.5, 11 and 150 mmol.L ${ }^{-1}$, respectively. ${ }^{16}$ Formulations are given in Table 1. 


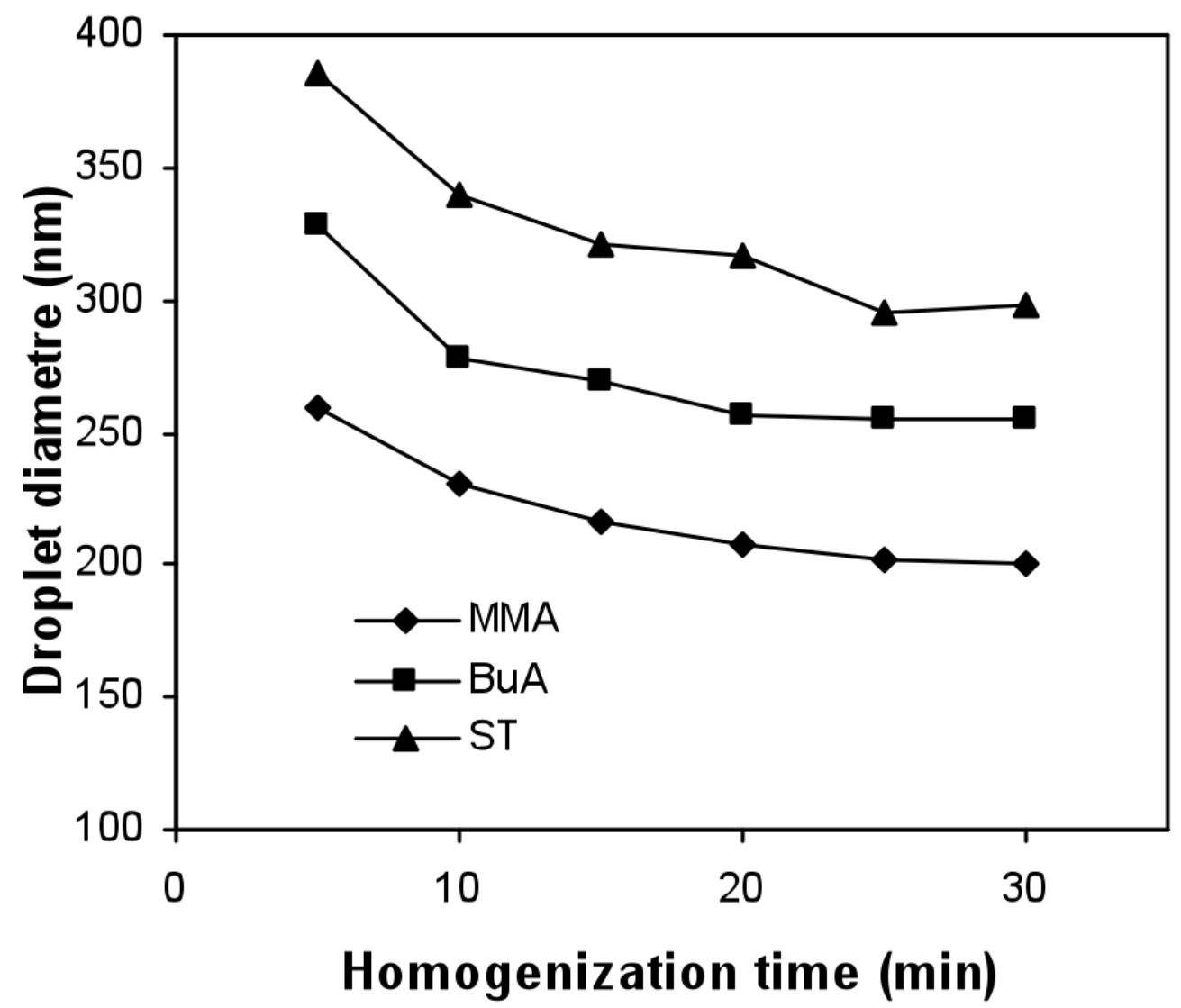

Figure 5. Evolution of the volume average droplet diameter for three different miniemulsifications using the PAC mixture and the formations in Table 1 for MMA, BA and STY as monomers. 


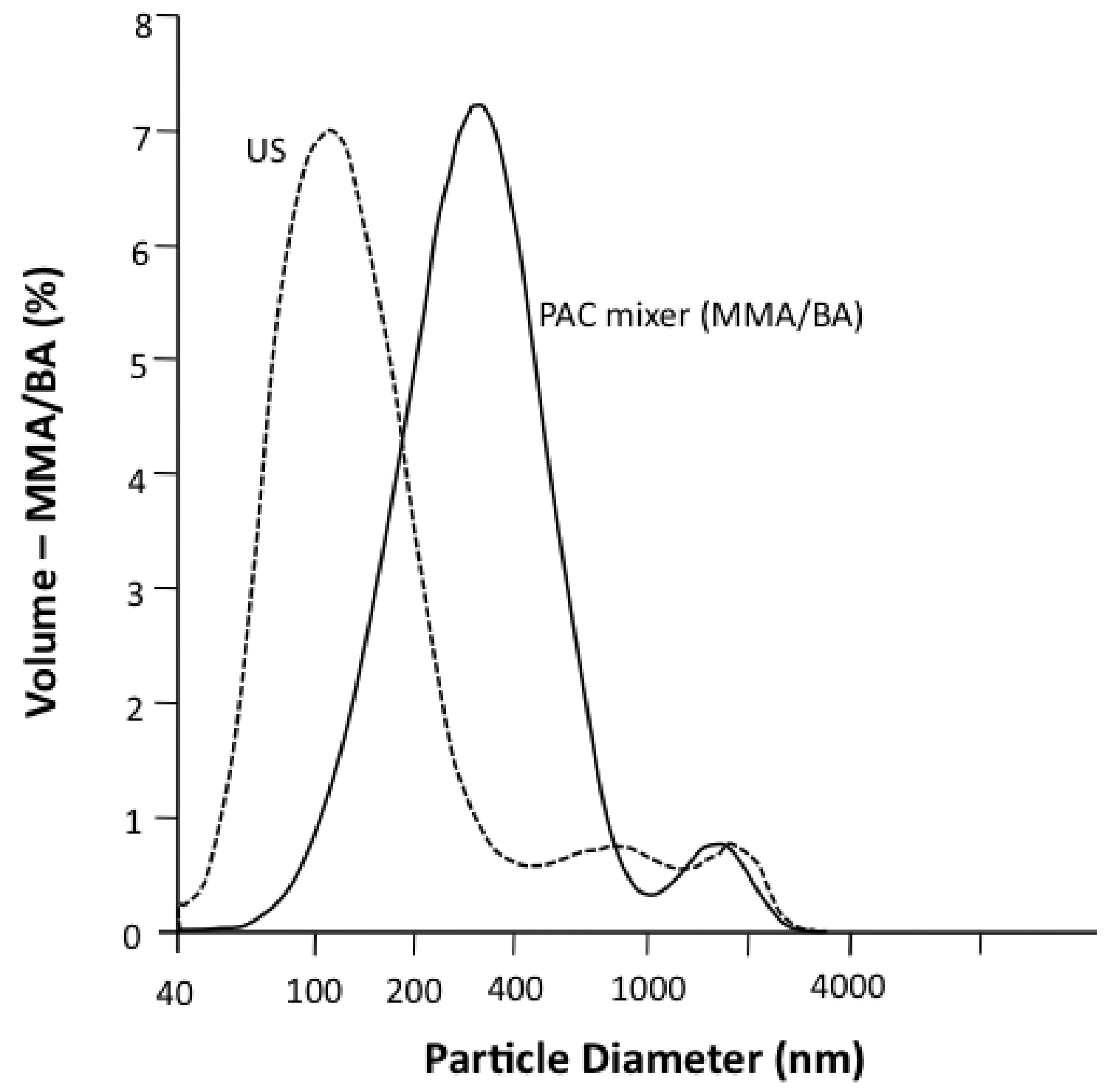

Figure 6. Droplet size distribution in miniemulsions of MMA+BA created by PAC static mixers and US for the formulations given in Table 1.

In order to understand the relationship between the impact of a change of formulation on the droplets generated in this manner, let us consider equation (1), that, in an ideal case (i.e. no coagulation or heat loss during emulsification), relates the energy required to break up droplets in a 2 phase system to form a surface area $\Delta \mathrm{A}$ (we will assume that the initial unemulsified system has a surface area of approximately zero):

$$
W_{\text {breakage }}=\gamma \cdot \Delta A=\gamma \cdot N_{p} \cdot V \cdot \pi d^{2}
$$

Equation 1

where $\gamma$ is the oil droplet/water interfacial tension, $\Delta A$ is the newly developed surface of droplets generated by homogenisation, $N_{p}$ is the number of particles per unit volume of 
emulsion, $V$ the emulsion volume, $d$ the average particle diameter, and $W_{\text {breakage }}$ is the work needed to generate this surface area. This expression can be rewritten in terms of d:

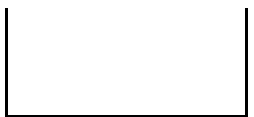

Equation 2

This expression tells us that the droplet diameter will vary as the inverse of the square root of the interfacial tension. Of course, this is an approximate representation of reality since it does not take into account the droplet size distribution, coalescence, heat losses, imperfectment mixing, etc. However it demonstrates clearly the relationship between the energy used for homogenisation and the formulation of the miniemulsion.

The interfacial tension of the four monomer systems investigated here (for the formulations in Table 1) was measured using the droplet volume method ${ }^{17}$, and the values for MMA+BA miniemulsions, MMA, BuA and STY are shown in Table 2. It can be seen from this table that the interfacial tension of the mixed monomer system is higher than that of MMA (and of BA also), but very close to that of STY. Therefore, if one wishes to obtain the same droplet size for both above emulsion systems, it would be necessary to do almost twice as much work on the MMA/BA system and the STY, than for MMA alone.

Table 2 Characteristics of miniemulsions created by SM

\begin{tabular}{lcccc}
\hline Parameter & MMA/BuA & MMA & BuA & ST \\
\hline$\gamma$ of Mini mN/m & 9.4 & 3.6 & 7.6 & 10 \\
\hline
\end{tabular}

The outcome of this analysis is that in order to emulsify the two monomer system (MMA/BA mixture or STY), it will be necessary to change the physical characteristics of the homogenisation set-up and/or the formulation. That a change of formulation only mildly improved the creation of a mixed miniemulsion, suggests that it is necessary to look at the impact of the mixing equipment on the droplet formation process. In addition, the fact that one can create stable miniemulsions using the US also suggests that the difficulties encountered in emulsifying the MMA/BA system are due more to the equipment than to the formulation. Since we wish to concentrate on using homogenisation systems that can be scaled up to pilot and commercial levels, US is not an option, so it was decided to look at the impact of the flow rate and the type of static mixer. 
Two modifications were made to the emulsification set-up, while keeping the same general configuration as shown in Figure 1. First, the PAC mixers were switched out in favour of the SMX mixers in a much shorter tube. A comparison between the two types of static mixers based on droplet evolution using the SDS formulation for MMA alone was performed. The results of the evolution of the droplet size distribution are shown in Figure 7. It is clear that all things being equal, the SMX mixers allow us to obtain smaller droplets.

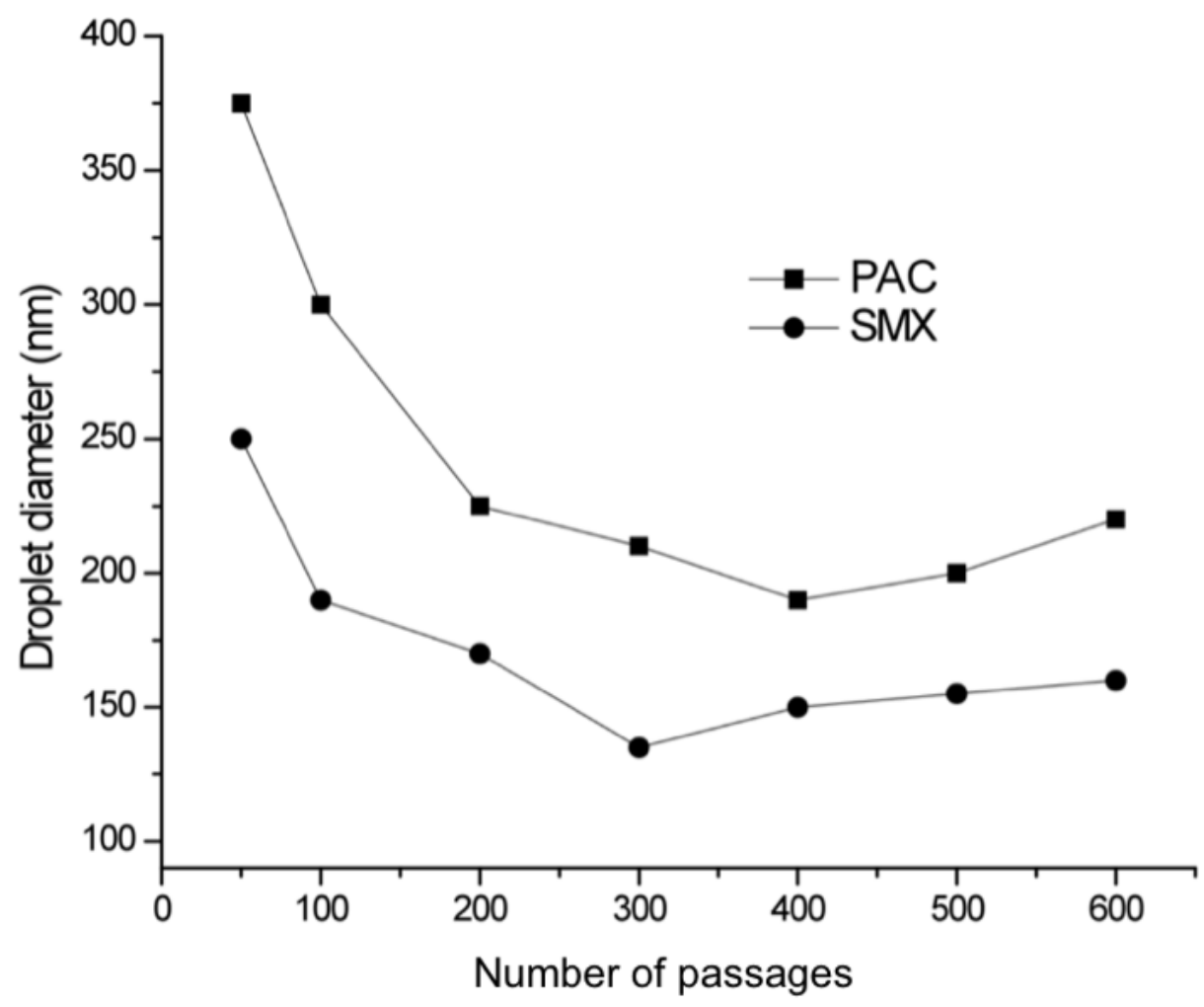

Figure 7. Droplet evolution over time generated using the PAC and SMX mixers for MMA and SDS.

The SMX mixers were therefore retained for the rest of the experiments presented in this study. The second modification to the set-up was to increase the energy dissipation in the SM zone, by replacing the original pump with one that allowed us to increase the flow rate from $61 \mathrm{~mL} \cdot \mathrm{s}^{-1}$ to $133 \mathrm{~mL} \cdot \mathrm{s}^{-1}$. The modified set-up was then used to explore the possibility of making polymerisable miniemulsions of a mixture of MMA/BA.

The droplet size distribution of a miniemulsion after 30 minutes of homogenisation of the mixture defined in Table 1 at a flow rate of $133 \mathrm{~mL} \cdot \mathrm{s}^{-1}$ over the SMX mixers is shown in Figure 8. This can be compared to the DSD of the same formulation with the PAC mixer 
shown in the previous section (Figure 3). Clearly the higher levels of energy dissipation available with this configuration allow us to break up the larger droplets that remain in the PAC system.

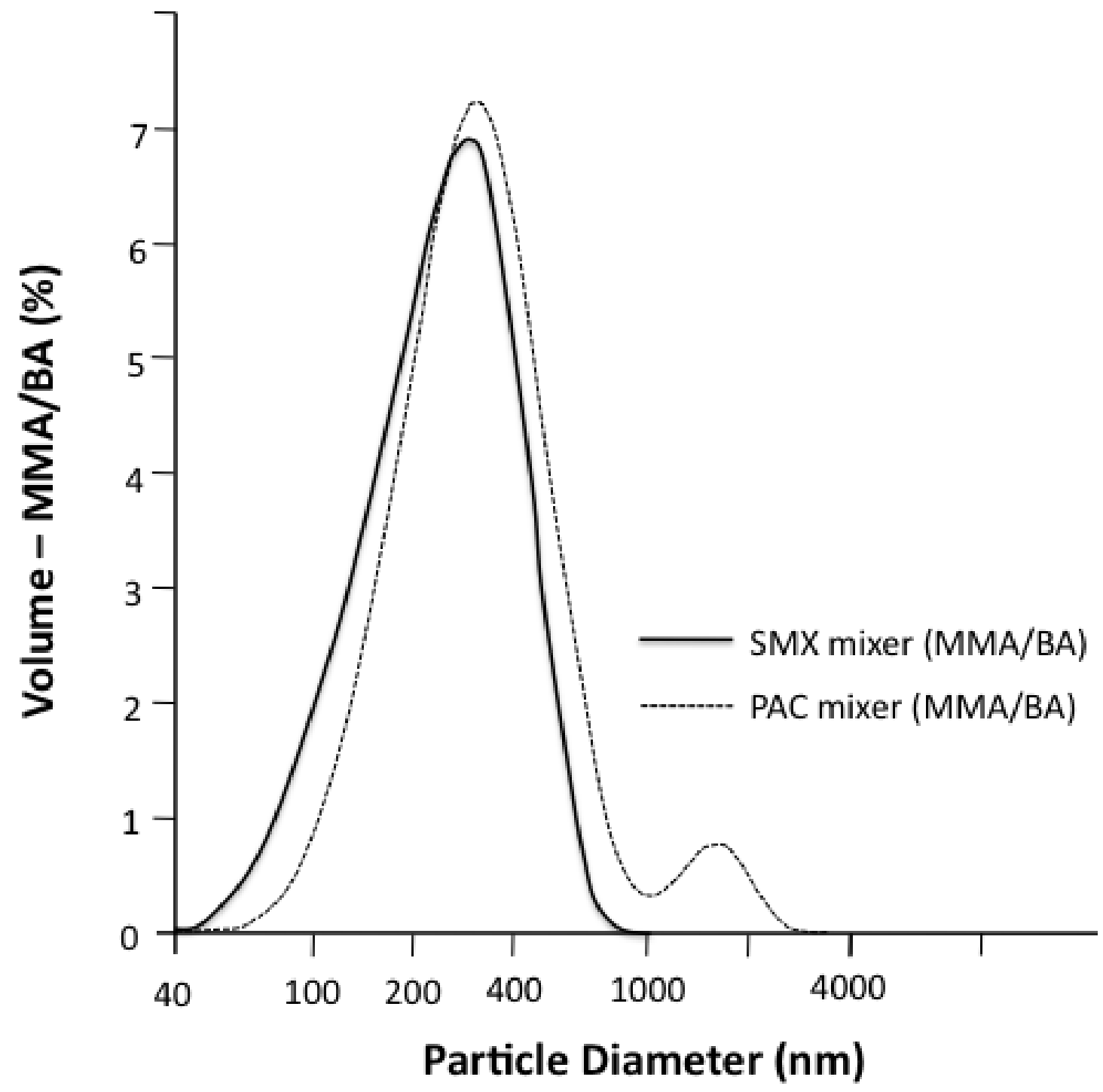

Figure 8. Droplet size distribution of $\mathrm{MMA}+\mathrm{BuA}$ miniemulsion after 30 minutes homogenisation with sulzer SM (solid line) compared to the DSD obtained using the PAC emulsifier (dotted line) using the formulation in Table 1.

The MMA+BA droplets generated in this manner after 30 minutes of homogenisation, were polymerised as described above. After 2 hours of reaction, the overall conversion was $97 \%$, and the value of $\mathrm{N}_{\mathrm{p}} / \mathrm{N}_{\mathrm{d}}=1.11$, demonstrating that these droplets could be successfully polymerised. 
Once MMA+BA droplets were successfully polymerised in this manner, hybrid MMA/BA miniemulsions containing different amounts of silica were prepared from a master batch of a relatively high concentrated dispersion of MPTMS-functionalised silica in monomers (35wt \% silica relative to MMA/BA 50/50 by weight) by diluting it to the desired concentration by adding monomer(s) prior to homogenisation. The MPTMS-functionalised silica was prepared using a procedure similar to that of Qi et al. ${ }^{18}$

Stable miniemulsions were created by homogenisation of silica-containing monomer dispersions in aqueous solution of surfactants using the set-up in Figure 1 and the improved process described above (SMX mixer, flow rate of $133 \mathrm{~mL} \cdot \mathrm{s}^{-1}$ ). The evolution of droplet size as a function of homogenisation time is illustrated in Figure 9 for different silica contents. As can be seen, the droplet size decreases as a function of homogenisation time as expected. The results also show that the droplet size increases with increasing silica content. The increase was moderate for low silica contents and became more important when the silica concentration increased to $15 \mathrm{wt} \%$. Note that similar sizes were obtained for $15 \mathrm{wt} \%$ and $20 w t \%$ silica. This could be due to the fact that for silica contents higher than $15 \%$, the viscosity of the dispersed phase is relatively high and the energy dissipated by SM might not be sufficient to break up the droplets. It is worth mentioning that similar results have been reported in the literature both for silica particles ${ }^{18}$ and titanium dioxide. ${ }^{19-21}$

The evolution of the polydispersity index (PDI) of the DSD of the miniemulsions as a function of silica content is plotted in Figure 10. It can be seen that the PDI increases as the silica content is increased. Again similar results were obtained by Qi et al. for silica. ${ }^{18}$ This suggests that the higher the silica content, the more difficult it is to maintain the stability of the droplets which leads to an increase in droplet size and droplet size distribution. 


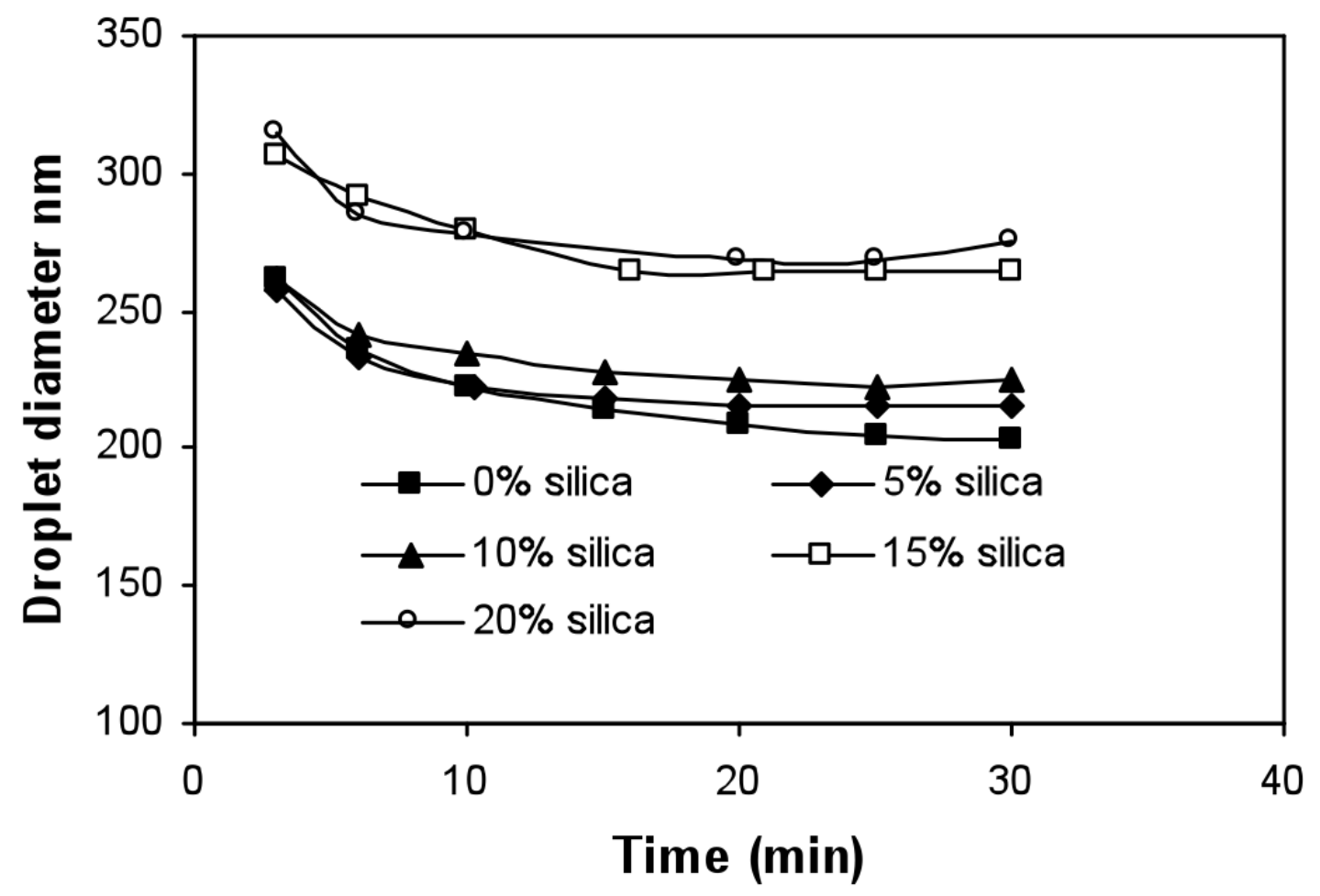

Figure 9. Evolution of droplet diameter versus homogenisation time.

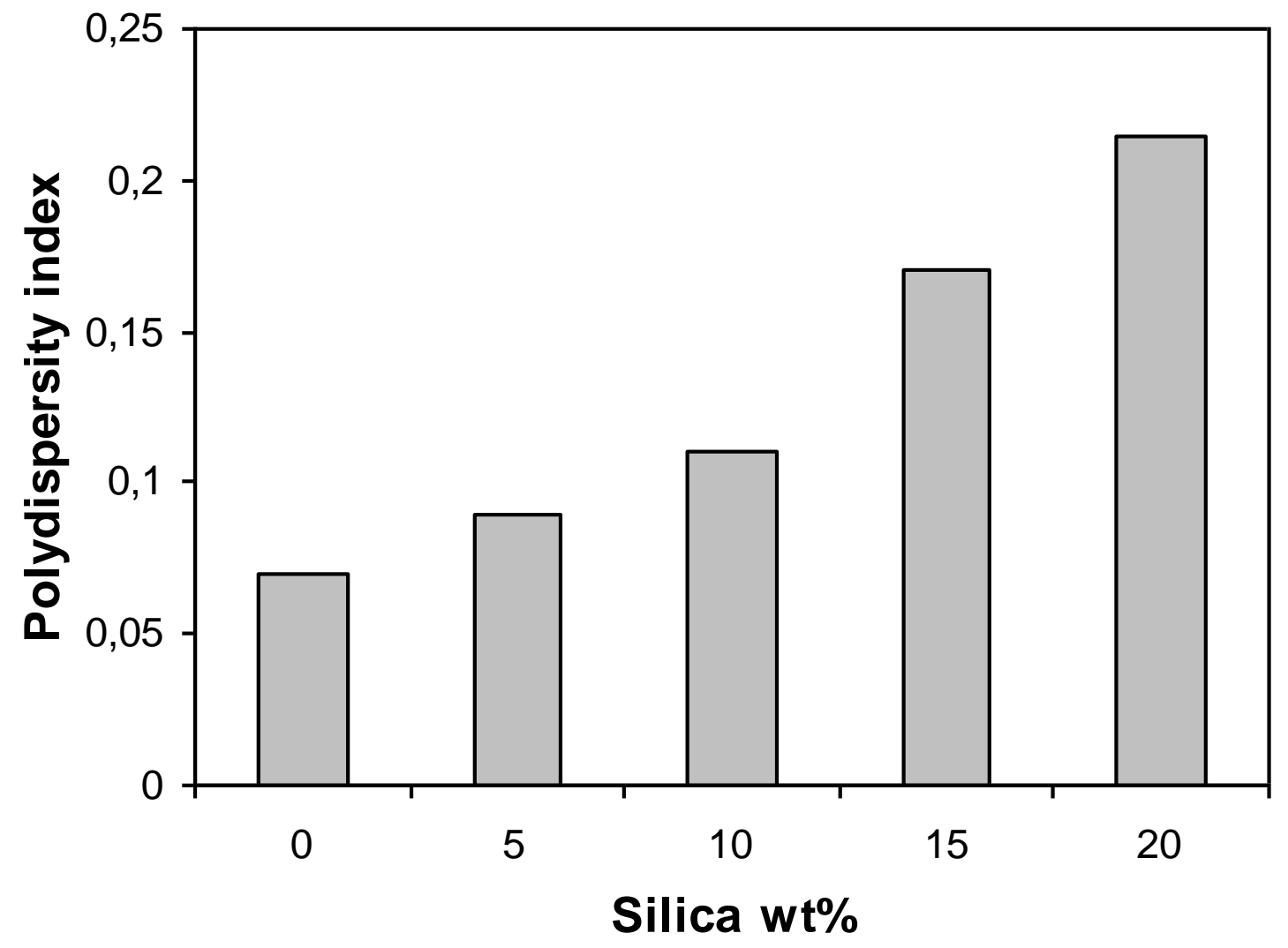

Figure 10. Evolution of polydispersity index as a function of silica content. 
The evolution of monomer conversion with time is shown in Figure 11 for silica contents varying from 0 to $20 \%$. The figure shows that there is no obvious influence of the silica on the monomer conversion. The evolution of $\mathrm{N}_{\mathrm{p}} \mathrm{N} / \mathrm{d}$ with polymerisation time is shown in Figure 12. As can be seen from this figure, a certain number of particles are generated at the beginning of polymerisation, especially at high silica loadings, indicating that particle renucleation is taking place. It is possible that this is due to the fact that the droplets are larger at higher silica loadings, meaning that more surfactant is available to stabilise any particles created by homogeneous nucleation.

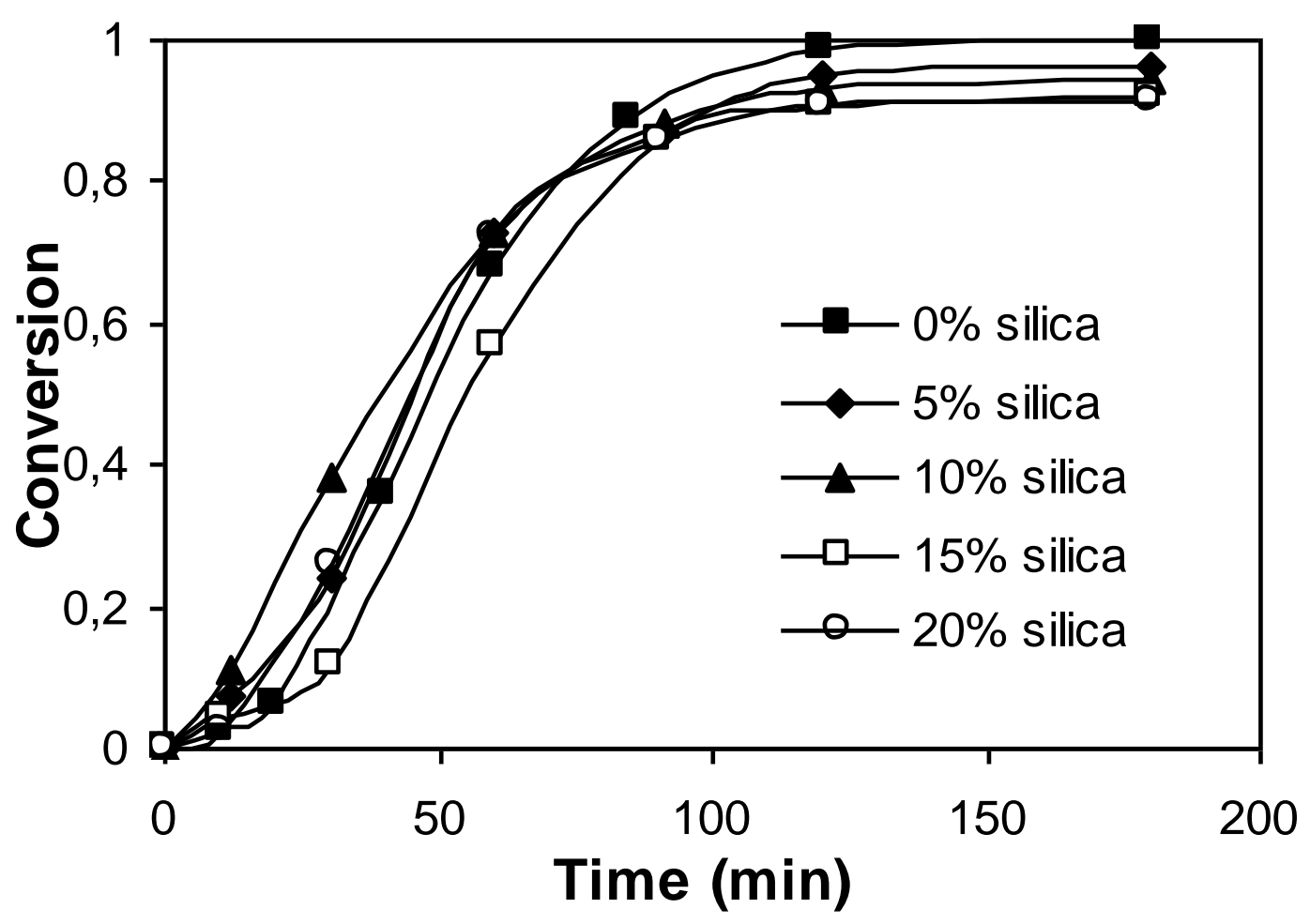

Figure 11. Conversion versus time curves of miniemulsion polymerization reactions performed using SMs as homogenisation device and MMA/BA (50:50 wt/wt) monomer mixtures containing increasing silica contents 


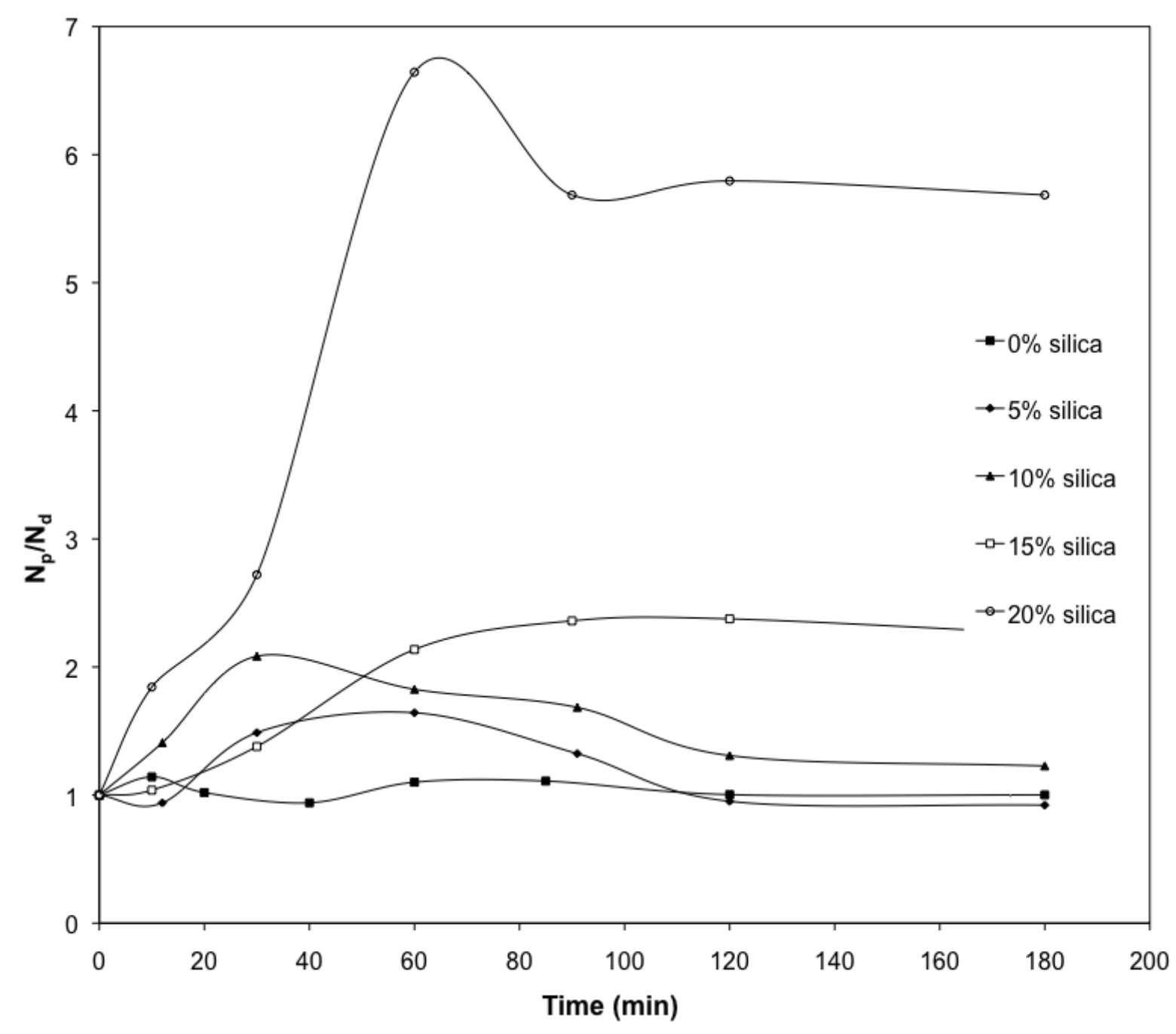

Figure 12. Evolution of $\mathrm{Np} / \mathrm{Nd}$ with time during miniemulsion polymerisation reactions performed using SMs as homogenisation device and MMA/BA (50:50 wt/wt) monomer mixtures containing increasing silica contents

\section{Conclusion}

It was shown that the emulsification of MMA+BA mixtures using PAC static mixers did not lead to the production of stable, well-defined miniemulsions regardless of the stabilisation system used. Similar experiments using US as homogenisation device showed that it is nonetheless possible to create polymerisable miniemulsions. An analysis of the interfacial tensions showed that while enough work can be done on either an MMA dispersion or a BA dispersion to make stable miniemulsions using the PAC, this was clearly not the case with the MMA+BA mixture because of its high interfacial tension. A similar conclusion was reached for STY dispersions for the same reason. 
By changing the static mixers and using a more powerful pump, it was shown possible to make MMA+BA miniemulsions using SMX mixers. The resulting miniemulsions were successfully polymerised. Finally, this set-up was used successfully to produce silicacontaining polymer particles. The majority of droplets were nucleated upon polymerization when less than $15 \%$ silica was used. However, when the silica content exceeded $15 \%, \mathrm{~N}_{\mathrm{p}} / \mathrm{N}_{\mathrm{d}}$ increased to value much higher than 1 indicating the occurrence of homogeneous nucleation.

\section{References}

1. Landfester, K., Macromol. Rapid. Commun. 2001, 22, P896-936.

2. Antonietti, M.; Landfester, K., Progress in Polymer Science 2002, 27, (4), 689-757.

3. Asua, J. M., Progress in Polymer Science 2002, 27, (7), 1283-1346.

4. Tesch, S.; Freudig, B.; Schubert, H., Chemical engineering Technology 2003, 26, (5), 569-573.

5. Freudig, B.; Tesch, S.; Schubert, H., Engineering in Life Sciences 2003, 3, (6), 266-270.

6. Ouzineb, K.; Lord, C.; Lesauze, N.; Graillat, C.; Tanguy, P. A.; McKenna, T.F.L., Chemical Engineering Science 2006, 61, (9), 2994-3000.

7. El-Jaby, U., Cunningham, M., Enright, T., McKenna, T.F.L., Macromolecular Reaction Engineering 2008, 4, 350-360

8. Seid Mahdi, J.; Yinghe, H.; Bhesh, B., International Journal of Food Properties 2006, 9, (3), 475-485.

9. Abismail, B.; Canselier, J. P.; Wilhelm, A. M.; Delmas, H.; Gourdon, C., Ultrasonics Sonochemistry 1999, 6, (1-2), 75-83.

10. Schork, F. J.; Luo, Y.; Smulders, W.; Russum, J. P.; Butte, A.; Fontenot, K., Advances in Polymer Science 2005, 175, (Polymer Particles), 129-255.

11. Yuh-Fun, M.; Chung, C. H., Pharmaceutical Development and Technology 1999, 4, (2), 233-240.

12. Farzi, G. A., Bourgeat-Lami, E., McKenna, T. F. L., Journal of applied polymer since 2009, 114, (6), 3875 - 3881.

13. Bakker, A.; Laroche, R. D.; Marshall, E. M., Laminar flow in static mixer with helical elements. In The online CFM Book: 1998.

14. Bone, S. Etude d'un procedes de fabrication de microcapsules par emulsification dans un melangeur statique. Université de Nantes, Nantes, 2005. 
15. Bourgeat-Lami, E.; Lang, J., Journal of Colloid and Interface Science 1998, 197, (2), 293-308.

16. Brandrup, J.; Immergut, E. H.; Grulke, E. A., Polymer hand book. Fourth ed.; Wiley interscience: New York, 1989.

17. Lando, J. L.; Oakley, H. T., Journal of Colloid and Interface Science 1967, 25, (4), 526530.

18. Qi, D-m.; Bao, Y-z.; Weng, Z-x.; Huang, Z-m., Polymer 2006, 47, (13), 4622-4629.

19. Erdem, B.; Sudol, E. D.; Dimonie, V. L.; El-Aasser, M. S., Journal of Polymer Science Part A: Polymer Chemistry 2000, 38, (24), 4419-4430.

20. Erdem, B.; Sudol, E. D.; Dimonie, V. L.; El-Aasser, M. S., Journal of Polymer Science Part A: Polymer Chemistry 2000, 38, (24), 4431-4440.

21. Erdem, B.; Sudol, E. D.; Dimonie, V. L.; El-Aasser, M. S., Journal of Polymer Science Part A: Polymer Chemistry 2000, 38, (24), 4441-4450. 